\title{
Biceps Brachii Muscle Innervation Zone Location in Healthy Subjects Using High-Density Surface Electromyography
}

\author{
Ubicación de la Zona de Inervación del Músculo Bíceps Braquial en \\ Sujetos Sanos Mediante Electromiografía de Superficie de Alta Densidad
}

Rodrigo A. Guzmán; Rony A. Silvestre \& David A. Arriagada

GUZMÁN, R. A.; SILVESTRE, R. A. \& ARRIAGADA, D. A. Biceps brachii muscle innervation zone location in healthy subjects using high-density surface electromyography. Int. J. Morphol., 29(2):347-352, 2011.

SUMMARY: Among the sequelae of central nervous system injury is spasticity which is difficult to manage in rehabilitation. Current treatments consider the administration of the botulinum toxin. However, results have proved highly variable in terms of effectiveness, attributable to the distance between the injection site and the innervations-zone (IZ). High Density sEMG (HDsEMG) has been used to gather information about muscle physiology and for location of the IZ. The aim of this study was to characterize the IZ of the biceps brachii muscle in healthy subjects during isometric contraction. We assessed the biceps brachii muscle of twenty healthy subjects $(n=20)$ using a 64 surface electrodes matrix. The average location of the IZ was $34 \%$ distal to the line between the cubital fossa and the anterior acromion.

KEY WORDS: Innervation zone; High density EMG; Motor unit; Muscle; Biceps brachii muscle.

\section{INTRODUCTION}

In traumatic or congenital neurological lesions one of the most frequent complications is spasticity. Among the therapeutic resources adopted for its treatment is the application of Botulinum toxin. Recent research has shown that the closer the application of the toxin to the innervationzone (IZ) plays a key role in treatment efficiency (Lapatki et al., 2009). The IZ corresponds to the anatomical site of the neuromuscular junction (Masuda et al., 1983; Masuda \& Sodoyama, 1987, 1988, 1989). The IZ location is related to muscle architecture and presents intra and inter muscular variations (Coers, 1958). Available methods to determine the location of the IZ comprise histochemical techniques (Aquilonius et al., 1984), invasive electrophysiological records (Buchthal, 1982; Wiederholt, 1970), electrostimulation (Childers, 2003), anatomic references (Perotto, 2005) and high density surface electromyography (HDSEMG) (Masuda et al.; Masuda \& Sadoyama, 1987; Masuda \& Sadoyama, 1989; Saitou et al., 2000; Merletti et al., 2003; Östlund et al., 2007; Beck et al., 2008; Merletti et al., 2008).

Technological advances in instrumentation have made possible the development of newer, better and less invasive electrophysiological techniques like HDSEMG. This technique measures electrical muscle activity generated by contraction with multiple closely spaced electrodes overlying a restricted area of the skin (Merletti et al., 2008; Farina \& Falla, 2008; Troiano et al., 2008; Falla et al., 2010).

Locating the IZ with better precision and non invasive procedures is appealing to clinical practice, especially when precision in IZ location is relevant for treatment outcome (e.g. administration of botulinum toxin in spasticity treatments) and procedure frequency. The purpose of this study is to describe the location of the biceps brachii muscle innervationzone using high density electromyography, given the potential use of this non-invasive technique in the location of the IZ.

\section{MATERIAL AND METHOD}

This research is a descriptive analytical pilot study. Through a convenience sample, a study group of twenty healthy male subjects was gathered $(n=20)$, whose average weight was $79.9 \mathrm{~kg}$ (standard deviation (SD) $\pm 11.0 \mathrm{~kg}$ and 
range: $64-86.8 \mathrm{~kg})$, mean height of $176.6 \mathrm{~cm}(\mathrm{SD} \pm 7.0 \mathrm{~cm}$ and range: $162-190 \mathrm{~cm}$ ) and average age of 22.4 years (SD \pm 3.2 years, range: $19-29$ years). Subject exclusion was applied using the following criteria: i. - any history of upper limb surgery, ii.- musculoskeletal and/ or nerve injury in the upper limb in the past six months, iii.- acute or subacute injury or infection of cutaneous and/or subcutaneous arm and forearm tissue. All subjects participated voluntarily and gave their consent in written form. All procedures carried out on sample subjects were approved by the ethics committee of the school of Kinesiology of the Universidad Mayor.

Instrumentation. For HDSEMG recording, a flexible twodimensional matrix of 64 surface electrodes of $2 \mathrm{~mm}$ of diameter was used and an inter-electrode distance of $8 \mathrm{~mm}$ (OT Bioelettronica. Torino, Italy). The 64 electrodes were arranged within the matrix of five columns, where the first four had 13 and the last column only had 12 electrodes. Detail of the matrix is presented in Fig. 1a.

The HDSEMG records of the 64 electrodes were amplified in a simple differential configuration obtaining 59 signals (Fig. 1b) using a HDSEMG equipment in a 10$750 \mathrm{~Hz}$ bandwidth (OT USB-EMG. Bioelettronica. Torino, Italy). A $2 \mathrm{k}$ gain was selected for the 64 electrodes. The analog-digital conversion was performed at a sampling frequency of $2048 \mathrm{~Hz}$ at 12 bits of resolution (OT Bioelettronica. Torino, Italy).

Procedure. Each subject anterior right arm skin was shaved with a disposable razor and then washed with water and soap. The location of the cubital fossa and the anterior acromion

(a)

(b)

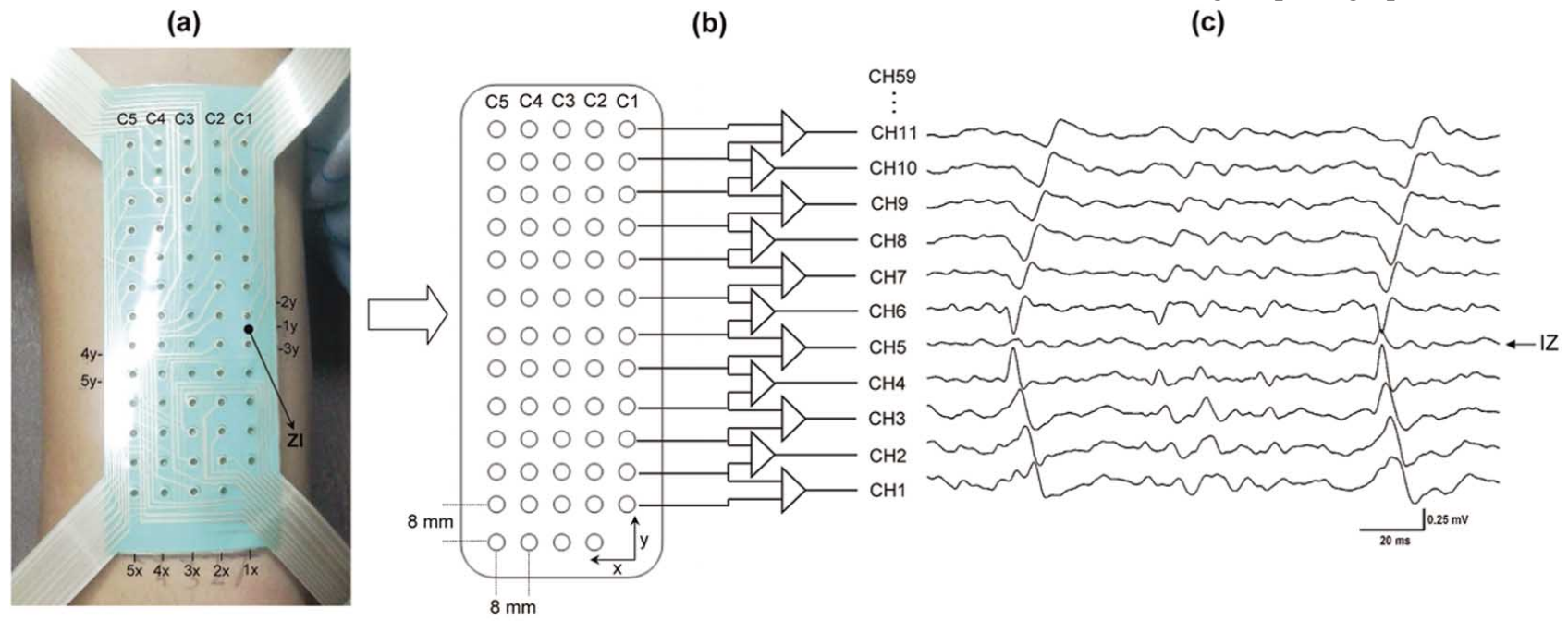

was marked with a dermographic pencil. The distance between the two structures $\left(D_{C F-A A}\right)$ was recorded. The matrix was placed in the arm of each subject so that its lower edge coincided with the $20 \%$ of $D_{C F-A A}$ and the internal border with the medial limit of the biceps brachii muscle, ensuring that matrix columns were parallel to the muscle fibers. The matrix was attached to the skin with a double contact hypoallergenic adhesive (OT Bioelettronica. Torino, Italy). With the aim of eliminating air interface and improving skinelectrode contact about $20 \mathrm{~mL}$ of conductive gel was applied between the electrodes and skin.

After checking signal quality, the elbow joint was fixed in partial flexion $\left(170^{\circ}\right.$ between forearm and arm segments) and each individual was asked to perform three submaximal isometric contractions against a manual resistance, separated by 30 seconds each. All signals were recorded for later analysis.

Innervation-zone identification. Through visual inspection of the motor unit action potential (MUAP) registered for each column, the XY coordinates were identified inside the electrode matrix where an inversion of the MUAP was observed and which corresponded to the IZ (Figs. 1c and 2). All IZ coordinates were marked at the edges of the matrix when this was still fixed to the arm (Fig. 1a). The procedure was repeated for each column. Once the XY coordinates were identified the matrix was removed and the skin was marked at the intersection of the XY coordinates for each IZ. The location of each IZ was described based on the cranial-caudal distance between the cubital fossa and each IZ. Additionally, two graphic records of the matrix and IZ marked on the skin were taken with a digital photographic camera.

Fig. 1. (a) Matrix of 64 surface electrodes arranged in five columns from C1 (medial) to C5 (lateral), at the matrix borders the coordinates of the recognized innervation-zones for each column were marked. (b) Scheme of the differential amplification of the first column, and the 59 signals recorded from the 64 electrodes. (c) Action potentials of motor units of the biceps brachii muscle for $\mathrm{C} 1$, note that the innervation-zone is located between electrodes 5 and 6, corresponding to channel 5 (CH5). 
C3

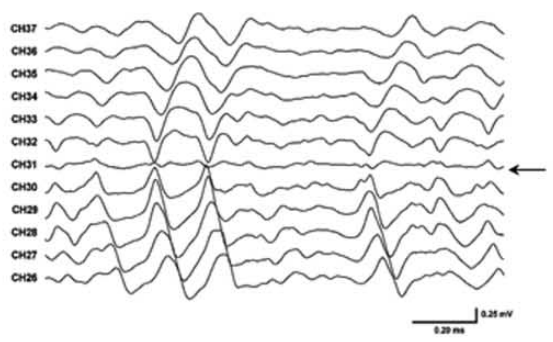

C2

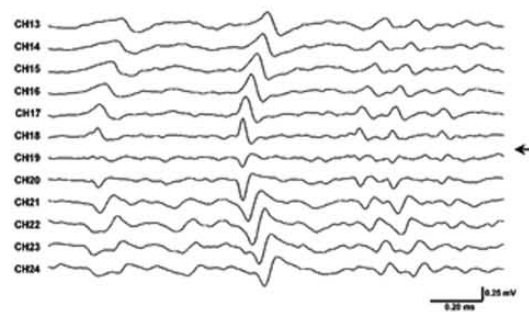

C1

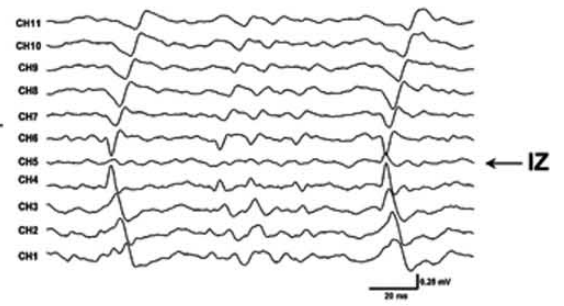

C5

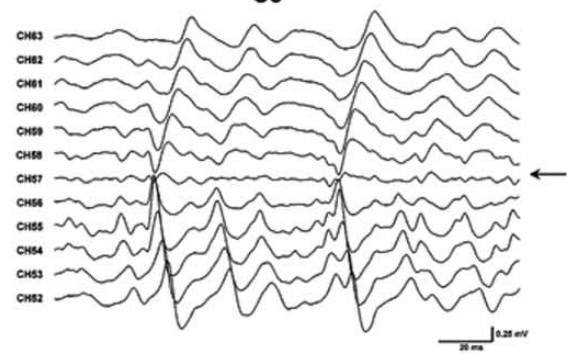

C4

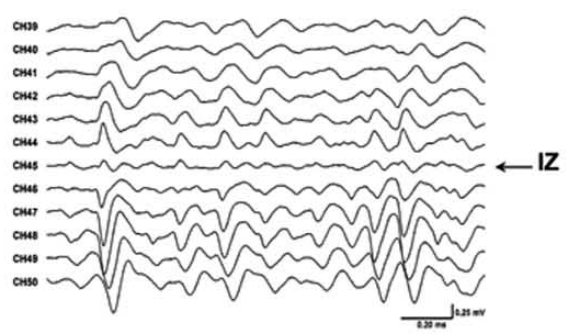

Fig. 2. Action potentials of motor units recorded by an array of 64 surface electrodes in the biceps brachii muscle. C1 corresponds to the most medial column and C5 to the most lateral. Arrows indicate the signal showing the location of the innervation-zone (IZ), in turn each signal corresponds to a known coordinate pair of electrodes, making it possible to identify the anatomical site corresponding to the IZ for each of the columns (C1-C5).
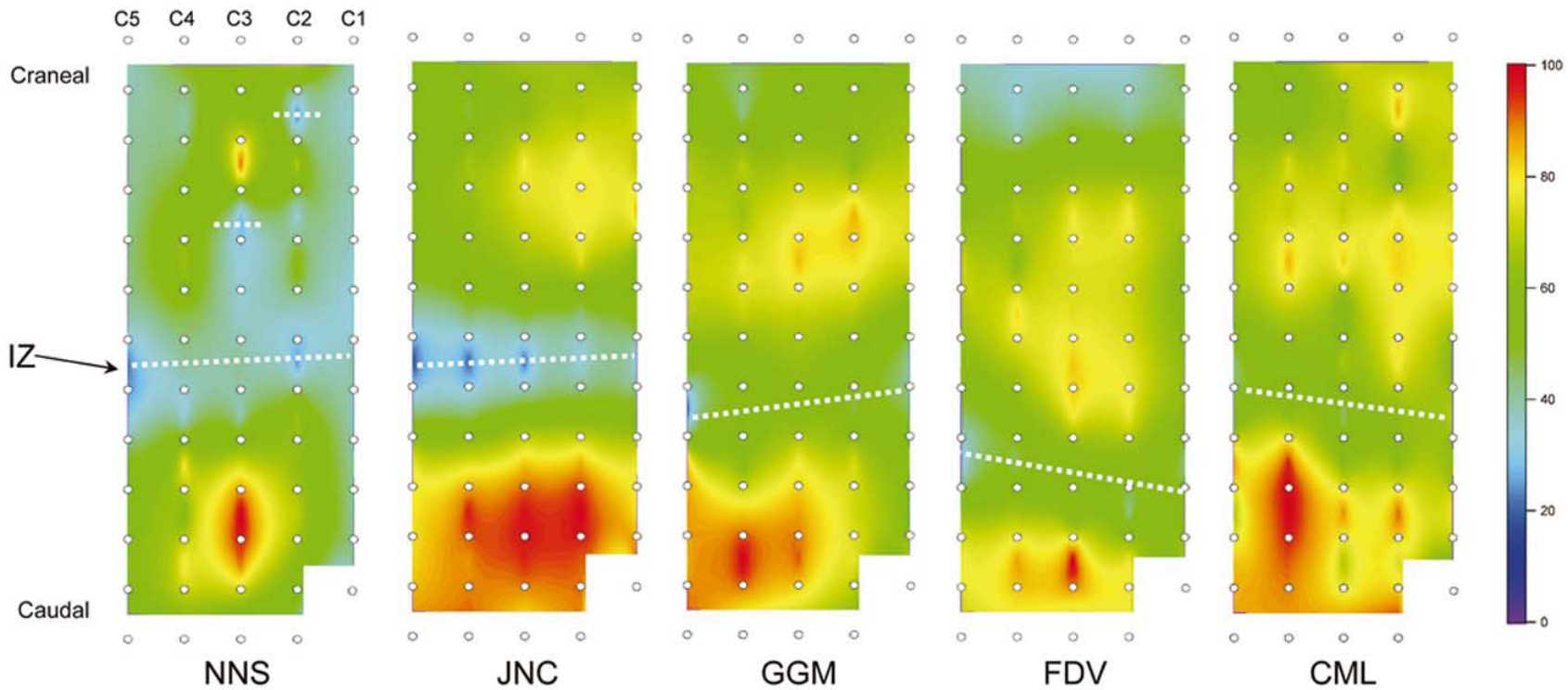

Fig. 3. Examples of topographic maps of electromyographic activity of the biceps brachii muscle from five subjects (NNS, JNC, GGM; VSF and CML), obtained by high density surface electromyography (HDSEMG). Signals amplitude were calculated using the root mean square in windows of $250 \mathrm{~ms}$, amplitude values for each window were adjusted to the maximum value of each windows and expressed as a percentage of this. For the construction of maps, amplitude values were multi-directional interpolated eight times. White dotted lines indicate the direction of the innervation-zone (IZ). Note that in subject NNS columns C2 and C3 show a double ZI.

Data processing. The location of the innervation-zone for each of the columns was adjusted to the DCF-AA of each subject and expressed as a percentage of that distance $\left(\% D_{C F-A A}\right)$. When two or more IZ were found for a single column, these were averaged to obtain a single location.
Additionally, all HDSEMG signals were digitally filtered with a bandpass filter 20-400HZ (OT Biolab. V1.0. Bioelettronica OT. Torino, Italy) and exported to a data processing software (IgorPro. 6.1.2.1. WaveMatrics, Inc. Lake Oswego, Oregon, USA). Amplitude was calculated 
through the root mean square (RMS) in time windows of $250 \mathrm{~ms}$. From the RMS values and the XY coordinates of each of the 59 signals, a two-dimensional topographic map of myoelectric activity was created in order to obtain a graphical representation of the location of the innervation-zones (Fig. 3).

Statistical analysis. A descriptive statistic of IZ location data was performed using the Prism 5.0. GraphPad Software, Inc. All statistical analysis were performed with a $95 \%(\partial=0.05)$ confidence interval.

\section{RESULTS}

The location of the innervation-zone for each of the columns was described based on the mean and upper and lower limits of the 95\% confidence interval. The results for each column are

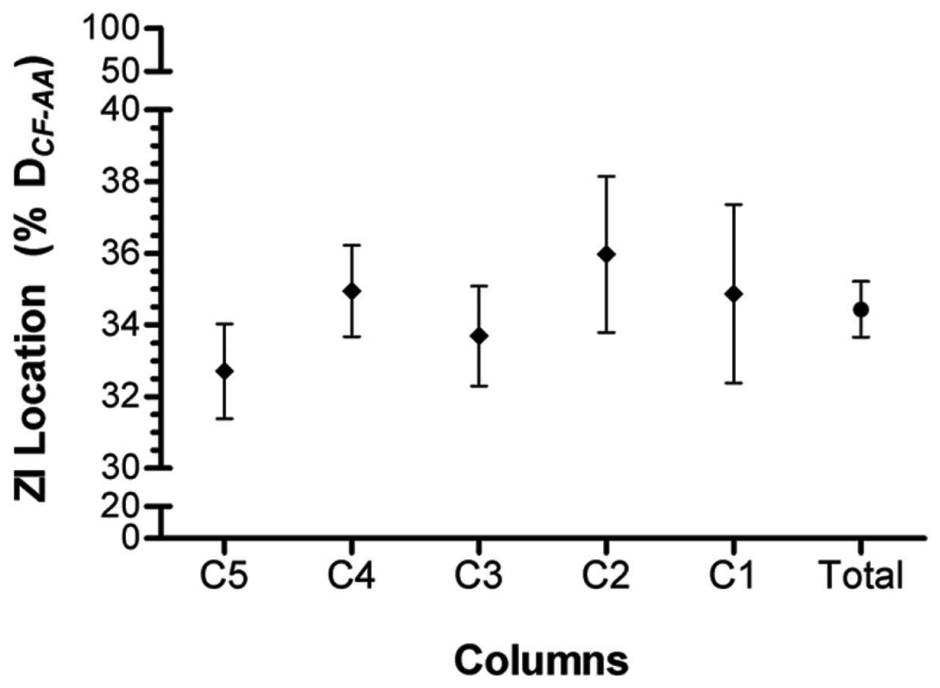

Fig. 4. Averages and confidence intervals at $95 \%$ of the location of the area of biceps brachii in twenty subjects $(n=20)$. Values are expressed as a percentage of the length between the cubital fossa and the anterior acromion (), $\mathrm{C} 1$ corresponds to the column over the most medial and lateral C5. Total indicates the average of all columns (C1-C5) with its respective confidence interval $95 \%$. summarized in Table I. Additionally, the average location and the upper and lower limits of the $95 \%$ confidence interval were calculated between all columns. All results are shown in Fig. 4. Figure 3 shows five examples of topographic maps of electrical muscle activity and their respective innervation areas for the biceps brachii muscle registered through HDSEMG.

\section{DISCUSSION}

The average location of the biceps brachii muscle innervation-zone in the studied group was close to the distal third, of the distance between the cubital fossa and the anterior acromion. Similar results have recently been published using a 16 electrode linear array type but with the elbow fixed at $90^{\circ}$ flexion (Barbero et al., 2010) Variation in the location of the innervation-zone seems to be low in the biceps brachii muscle. However, there are some individual cases where a double innervation-zone exists (E.g. Subject NNS, see figure 4). On the other hand, the location of the innervation-zone relative to the supra adjacent skin can be displaced from 5 to $30 \mathrm{~mm}$ as a result of elbow flexion (Martin \& MacIsaac, 2006). In our study this factor was controlled by fixing the elbow position at $170^{\circ}$ of flexion. Another element which can affect IZ location is the contraction level, but to a lesser degree. Piitulainen et al. (2009) reported a displacement of the IZ close to $4 \mathrm{~mm}$ in contractions below $40 \%$ of the maximum voluntary contraction (MVC) and between 6 to $8 \mathrm{~mm}$ in contractions ranging from 50 to $100 \%$ of the MVC. This factor was partially controlled in this study, given that subjects were asked for a sub maximum isometric contraction below $50 \%$ of the MVC, where the probable IZ displacement coincides with the spatial resolution $(4 \mathrm{~mm})$ of the electrode

Table I. Averages and upper and lower limits of the 95\% confidence interval (CI) and coefficient of variation (CV) of the location of the innervation-zone of the biceps brachii muscle. The first three descriptors are expressed as a percentage of the length between the cubital fossa and the anterior acromion (), CVs are expressed only in percentage. Data was collected from twenty subjects $(n=20)$. Total indicates the average of all columns. Column $\mathrm{C} 1$ is more medial and $\mathrm{C} 5$ is the more lateral.

\begin{tabular}{lcccccc}
\hline \multicolumn{2}{l}{ Table I. Biceps brachii innervation zone location $(\mathrm{n}=20)$} \\
\hline & $\mathrm{C} 5$ & $\mathrm{C} 4$ & $\mathrm{C} 3$ & $\mathrm{C} 2$ & $\mathrm{C} 1$ & Total \\
Mean $\left(\% \mathrm{D}_{C F-A A}\right)$ & 32.7 & 35.0 & 33.7 & 36.0 & 34.9 & 34.4 \\
IC 95\% Low $\left(\% \mathrm{D}_{C F-A A}\right)$ & 31.4 & 33.7 & 32.3 & 33.8 & 32.4 & 33.7 \\
IC 95\% Upper $\left(\% \mathrm{D}_{C F-A A}\right)$ & 34.0 & 36.2 & 35.1 & 38.2 & 37.4 & 35.2 \\
Coefficient Variation $(\%)$ & 8.7 & 7.8 & 8.8 & 12.9 & 15.3 & 11.4 \\
\hline
\end{tabular}


matrix (Inter-electrode distance 8mm, see Figure 1). Previous reports have identified the IZ in the biceps braquii muscle using surface electromyography (Saitou et al.; DeFreitas et al., 2010). However, in these studies linear "array" type electrodes but not two-dimensional matrixes were used. The disadvantage of using array type electrodes is that they can only identify the IZ one column at a time, therefore making it necessary to change the electrode position to locate the neighbouring IZ. This can vary conditions and increase measurement error as well as generate loss of spatial resolution in the location of the IZ. Also, the need to change the electrode position makes the data acquisition process much longer. On the other hand, Masuda \& Sodoyama (1991) used a 128 electrode matrix to evaluate a sample of only seven subjects but did not adjust the IZ location data to anatomic length.

In matrix columns $\mathrm{C} 1$ and $\mathrm{C} 2$ intervals, greater amplitude in the confidence intervals and in the coefficient of variation was observed, suggesting more variation in the location of the IZ in the corresponding territory of the short head of the biceps brachii muscle. The identification of the muscle IZ is of great assistance in cases of spasticity therapy using botulinum toxin injection (BT). This toxin inhibits acetylcholine liberation in the neuromotor plate located in the IZ. For the application of BT the neuromotor plate is usually used as the site of injection. Although locating of the motor plate can be achieved by needle electromyography there are some disadvantages to this method like a poor spatial resolution and the fact that the procedure is invasive. Another alternative is looking for the Muscular Motor Point (MMP) by electro stimulation. However, in this case locating is done on the skin supra adjacent to the muscle were the application of the electro stimulation generates a maximum mechanical response using a minimum current magnitude. From an anatomical and functional point of view, the MMP does not necessarily coincide with the IZ given that each corresponds to different concepts (Saitou et al.; Oprandi et al., 2010).

At present there is evidence that the place of injection of BT with respect to the IZ is fundamental for a successful outcome. When the toxin is applied distant to the motor plate, efficacy is reduced and can produce non desirable effects (E.g. the toxins "jumping effect" to the undamaged motor units). Lapatki et al. have recently reported that the application of the BT at a distance of $12 \mathrm{~mm}$ from the IZ produces a $74 \%$ reduction in its effect in comparison to when it is injected directly to the IZ. Based on this, selection of the BT injection site is critical for therapy effectiveness. Therefore, application of HDSEMG for locating the IZ is a potential and powerful tool for botulinum toxin and the recently developed gonyautoxin injection therapy plus the fact that it is a noninvasive procedure with a relatively high spatial resolution (Garrido et al., 2005).

In conclusion, through high-density surface electromyography it is possible to determine the location of innervation-zone of the biceps brachii muscle. The average location of the innervation-zone in our sample was $34 \%$ distal to the line between the cubital fossa and the anterior acromion. However, there is some variation in the distribution of the innervation-zone within this muscle, especially in its medial fascicles.

GUZMÁN, R. A.; SILVESTRE, R. A. \& ARRIAGADA, D. A. Ubicación de la zona de inervación del músculo bíceps braquial en sujetos sanos mediante electromiografía de superficie de alta densidad. Int. J. Morphol., 29(2):347-352, 2011.

RESUMEN: Entre las secuelas de lesiones del Sistema Nervioso Central se encuentra la espasticidad, la cual es de difícil manejo terapéutico. Los tratamientos actuales de la espasticidad consideran la administración de la toxina botulínica. Sin embargo, los resultados de su aplicación han sido muy variables en términos de eficacia, atribuible a las distintas distancias entre el lugar de inyección y la zona de inervación (ZI). La EMG de alta densidad se ha utilizado para recolectar información acerca de la fisiología muscular y para localizar la ZI. El objetivo de este estudio fue describir la ubicación de la ZI del músculo bíceps braquial en sujetos jóvenes sanos, durante una contracción isométrica. Evaluamos el músculo bíceps braquial en 20 sujetos sanos usando una matriz de 64 electrodos. El promedio de localización de la ZI fue de 34\% en el sentido distal de la línea trazada entre la fosa cubital y el acromion anterior.

PALABRAS CLAVE: Zona de inervación; EMG de alta densidad; Unidades motoras; Músculo; Músculo Bíceps braquial.

\section{REFERENCES}

Aquilonius, S. M.; Askmark, H.; Gillberg, P. G.; Nandedkar, S.; Olsson, Y. \& Stålberg, E. Topographical localization of motor endplates in cryosections of whole human muscles. Muscle Nerve, 7:287-93, 1984.

Barbero, M.; Tomasoni,E.; Piccoli, M.; Rozzi, M.; Boccia, G.; Merletti, R. \& Rainoldi, A. Atlas of muscle innervation zones for proper SEMG electrode placement: preliminary results. The XVII Congress of the International Society of Electrophysiology and Kinesiology. Aalborg, Denmark, 2010.

Beck, T.; Housh, T.; Cramer, J. \& Weir, J.; The effects of electrode placement and innervation zone location on the electromyographic amplitude and mean power frecuency versus isometric torque relationships for the vastus lateralis muscle. J. Electromyogr. Kinesiol., 18:317-28, 2008. 
Buchthal, F. Spontaneous electrical activity: an overview. Muscle Nerve, 5:S52-9, 1982.

Coers, C. Structural organization of the motor nerve endings in mammalian muscle spindles and other striated muscle fibers. Am. J. Phys. Med. Rehabil., 38:166-75, 1958.

Childers, M. The importance of electromyographic guidance and electrical stimulation for injection of botulinum toxin. Phys. Med. Rehabil. Clin. N. Am., 14:781-92, 2003.

DeFreitas, J.; Copsta, P.; Ryan, E.; Herda, T. \& Beck, T. Innervation zone location of the bíceps brachii, a comparison between genders and correlation with antropometric measurements. $J$. Electromyogr. Kinesiol., 20:76-80, 2010.

Falla, D.; Andersen, H.; Danneskiold-Samøe, B.; Arendt-Nielsen, L. \& Farina. D. Adaptations of Upper Trapezius muscle activity during sustained contractions in women with fibromyalgia. J. Electromyogr. Kinesiol., 20:457-67, 2010.

Farina, D. \& Falla, D. Estimation of muscle fiber conduction velocity from two-dimensional surface EMG recording in dynamics tasks. Biomed. Signal. Process. Control, 3:138-44, 2008.

Garrido, R.; Lagos, N.; Lattes, K.; Abedrapo, M.; Bocio, G.; Cuneo, A.; Chiong, H.; Jensen, C.; Azolas, R.; Henriquez, A. \& Garcia, C. Gonyautoxin: New treatment for healing acute and chronic anal fissures. Dis. Colon Rectum, 48:335-43, 2005.

Masuda, T. \& Sodoyama, T. Distribution of innervation zones in the human bíceps brachii. J. Electromyogr. Kinesiol., 1:10715,1991 .

Martin, S. \& MacIsaac, D. Innervation zone shift with changes in joint angle in the brachial biceps. J. Electromyogr. Kinesiol., 16:144-8, 2006.

Masuda, T.; Miyano, H. \& Sadoyama, T. The propagation of motor unit action potential and the location of neuromuscular junction investigated by surface electrode arrays. Electroenceph. Clin. Neurophysiol., 55:594-600, 1983.

Masuda, T. \& Sadoyama, T. Skeletal muscles from which the propagation of motor unit action potentials is detectable with a surface electrode array. Electroenceph. Clin. Neurophysiol., 67:421-7, 1987.

Masuda, T. \& Sodoyama, T. Topographical map of innervation zones within single motor units measured with a grid surface electrode. IEEE. Trans. Biomed. Eng., 35:623-8, 1988.

Masuda, T. \& Sadoyama, T. Processing of myoelectric signals for estimating the location of innervation zones in the skeletal muscles. Front. Med. Biol. Eng., 1:299-314, 1989.
Merletti, R.; Farina, D. \& Gazzoni, M. The linear electrode array: a useful tool with many applications. J. Electromyogr. Kinesiol., 13:37-47, 2003.

Merletti, R.; Holobar, A. \& Farina, D. Analysis of motor units with high-density surface electromyography. J. Electromyogr. Kinesiol., 18:879-90, 2008.

Lapatki, B.; Van Dijk, J.; Van de Warrenburg, M. \& Zwarts, M. High-density surface electromyography guided botulinum toxin injection. Clin. Neurophysiol., 12:e89-e126, 2009.

Oprandi, G.; Botter, A.; Lanfranco, F.; Merletti, R. \& Minetto, M. Atlas of the muscle motor points for lower limb muscle. The XVIII Congress of International Society of Electrophysiology and Kinesiology, Aalborg, Denmark, 2010.

Östlund, N.; Gerdle, B. \& Karlsson, J. S. Location of innervation zone determined with multichannel surface electromyography using an optical flow technique. J. Electromyogr. Kinesiol., 17:549-55, 2007.

Perotto, A. Anatomical guide for the electromyographer. $4^{\text {th }}$ Ed. Springfield, Charles C. Thomas Publisher, 2005.

Piitulainen, H.; Rantalainen, T.; Linnamo, V.; Komi, P. \& Avela, J. Innervation zone shift at different levels of isometric contraction in the biceps brachii muscle. J. Electromyogr. Kinesiol., 9:667-75, 2009.

Saitou, K.; Masuda, T.; Michikami, D.; Kojima, R. \& Okada, M. Innervation zones of upper and lower limb muscles estimated by using multichannel surface EMG. J. Human Ergol., 29:35$52,2000$.

Troiano, A.; Naddeo, F.; Sosso, E.; Camarota, G.; Merletti, R. \& Mesin, L. Assessment of force and fatigue in isometric contractions of the upper trapezius muscle by surface EMG signal and perceived exertion scale. Gait Posture, 28:179-86, 2008 .

Wiederholt, W. End-plate "noise" in electromyography. Neurology, 20:214-24, 1970.

Dirección para correspondencia:

Rodrigo A. Guzmán.

Centro de Estudios del Movimiento Humano

Universidad Mayor

Escuela de Kinesiología

Facultad de Medicina

Camino La Piramide 5750

Recibido : 23-11-2010

Huechuraba, Santiago, 8580745

CHILE

Email: rodrigoguzmanvenegas@gmail.com 